\title{
West Nile Virus Activity in a Winter Roost of American Crows (Corvus brachyrhynchos): Is Bird-To-Bird Transmission Important in Persistence and Amplification?
}

\author{
M. G. HINTON,${ }^{1,2}$ W. K. REISEN,${ }^{3}$ S. S. WHEELER, ${ }^{3}$ AND A. K. TOWNSEND ${ }^{1,4}$
}

J. Med. Entomol. 52(4): 683-692 (2015); DOI: 10.1093/jme/tjv040

\begin{abstract}
Since its emergence in North America, West Nile virus (WNV) has had a large impact on equines, humans, and wild bird communities, yet gaps remain in our understanding of how the virus persists at temperate latitudes when winter temperatures preclude virus replication and host-seeking activity by mosquito vectors. Bird-to-bird transmission at large communal American Crow roosts could provide one mechanism for WNV persistence. Herein, we describe seasonal patterns of crow and Culex mosquito abundance, $\mathrm{WNV}$ infection rates, and the prevalence of WNV-positive fecal samples at a winter crow roost to test the hypothesis that bird-to-bird transmission allows WNV to persist at winter crow roosts. Samples were collected from large winter crow roosts in the Sacramento Valley of California from January 2013 until August 2014, encompassing two overwintering roost periods. West Nile virus RNA was detected in local crow carcasses in both summer [13/18 (72\% WNV positive)] and winter [18/44 (41\% WNV positive)] 2013-2014. Winter infections were unlikely to have arisen by recent bites from infected mosquitoes because Culex host-seeking activity was very low in winter and all Culex mosquitoes collected during winter months tested negative for WNV. Opportunities existed for fecal-oral transfer at the overwintering roost: most carcasses that tested positive for WNV had detectable viral RNA in both kidney and cloacal swabs, suggesting that infected crows were shedding virus in their feces, and $>50 \%$ of crows at the roost were stained with feces by mid-winter. Moreover, $2.3 \%$ of fecal samples collected in late summer, when mosquitoes were active, tested positive for WNV RNA. Nevertheless, none of the 1,119 feces collected from three roosts over two winters contained detectable WNV RNA. This study provided evidence of WNV infection in overwintering American crows without mosquito vector activity, but did not elucidate a mechanism of WNV transmission during winter.
\end{abstract}

KEY WORDS West Nile virus, American Crow, Corvus brachyrhynchos, Culex, bird-to-bird transmission

In 1999, an outbreak of West Nile Virus (WNV), a zoonotic mosquito-borne flavivirus, led to morbidity and mortality in humans, horses, and multiple avian species in New York and adjacent states (Komar 2003). Widespread mortality among American Crows was and continues to be the hallmark of this on-going outbreak (Eidson et al. 2001). Since the virus's emergence, WNV has been a frequent cause of viral encephalitis in equines and humans within the United States (Azad and Thomas 2004, Petersen et al. 2012), and infection has been recorded naturally in $\sim 326$ avian species, spanning across most native North American avian orders (Marra et al. 2004, Centers for Disease Control [CDC]

\footnotetext{
${ }^{1}$ Department of Wildlife, Fish, \& Conservation Biology, University of California, Davis, 1088 Academic Surge, Davis, CA 95616

${ }^{2}$ Corresponding author, e-mail: mghinton@ucdavis.edu.

${ }^{3}$ Department of Pathology, Microbiology, \& Immunology, University of California, Davis, Center for Vectorborne Diseases, Old Davis Road, Davis, CA 95616.

${ }^{4}$ Department of Biology, Hamilton College, Clinton, NY 13323.
}

2009). Despite widespread impact on both avian and human communities, gaps remain in our understanding of WNV transmission dynamics, particularly how the virus persists in temperate climates when cold temperatures preclude viral replication and diminish vector blood-feeding activity (Reisen et al. 2006b). Overwintering mechanisms are critically important because they determine the prevalence of virus at the termination of winter and thereby may dictate the force of transmission during vernal amplification. This was shown in a study conducted in the Coachella Valley, $\mathrm{CA}$, in which intense early-season intervention at an overwintering focus markedly delayed viral amplification and dispersal (Lothrop et al. 2008).

The transmission cycle of WNV is dependent upon competent mosquito vectors and susceptible birds intersecting within a permissive environment (Campbell et al. 2002, Marra et al. 2004, Allan et al. 2009, Hamer et al. 2009, Egizi et al. 2014). Ornithophagic species within the genus Culex are important vectors and responsible for zoonotic WNV transmission among birds 
(Molaei et al. 2006). Culex in California are quiescent or diapause during cold winter months (Nelms et al. 2013a,b), and low temperatures hinder WNV replication within the overwintering mosquito hosts (Dohm et al. 2002, Reisen et al. 2006b). Nevertheless, researchers in New York State documented American Crow (Corvus brachyrhynchos; hereafter "crow") mortality during February and March of 2005 (Dawson et al. 2007). Overall, $12.2 \%$ of carcasses and $6.7 \%$ (3 of 45) of fecal specimens tested positive for WNV. Due to low temperatures and a lack of observable mosquito activity, crow WNV infections were attributed to birdto-bird transmission. Other studies have corroborated the presence of WNV in winter crow carcasses (Wheeler et al. 2014), and recent work has demonstrated that water-borne fecal-oral transmission could drive WNV infection and mortality in overwintering waterfowl (Ip et al. 2014).

Several lines of evidence suggest that crows might play an important role in the WNV transmission cycle. Crows are a widespread, synanthropic, and highly competent host for WNV (Komar et al 2003). In their mechanistic model developed to track the invasion of WNV into California, Hartley et al. (2012) showed that outbreaks are unlikely to occur in the absence of crows or other highly competent amplification hosts. Moreover, in southern California, foci of WNV infection in Culex and humans generally overlapped with areas of high crow density and mortality, suggesting the importance of corvids in amplification of the virus (Reisen et al. 2006a). Crow roosts could potentially provide an efficient overwintering reservoir for WNV. Winter crow roosts can number in the tens of thousands of birds and are common in cities throughout North America (Gorenzel and Salmon 1995). Crows develop high levels of viremia postinfection (Komar et al. 2003, Marra et al. 2004, Bowen and Nemeth 2007), and can shed high titers of WNV in feces (documented in the laboratory, Kipp et al. 2006). Furthermore, contact transmission has been documented in the laboratory (Komar et al. 2003). It is possible that bird-to-bird (fecal-oral) transmission occurs at large roosts when roosting birds defecate on one another and subsequently preen themselves or preen other birds (allopreen). This effective persistence mechanism might enable rapid vernal amplification of $\mathrm{WNV}$ when competent mosquito vectors become abundant in the warmer months. If this is indeed the case, there should be evidence of continuous transmission among crows in or around communal winter roost sites.

The purpose of our study was to elucidate the extent and mechanisms by which WNV persists at communal winter roosts of American Crows in the Sacramento Valley of California. We describe the seasonal patterns of crow and Culex mosquito abundance, WNV infection rates, and the prevalence of WNV-positive fecal samples at a winter crow roost. Furthermore, we assess the opportunity for fecal-oral infection of WNV at the roost by recording seasonal rates of feather staining (i.e., percentage of birds with feces on feathers), by examining seasonal patterns of WNV infection in dead crows, and by comparing levels of virus in crow carcasses and feces. We used these data o test the specific hypotheses that 1 ) WNV infection occurs within winter crow roosts in the absence of mosquitoes and that 2) WNV infection occurs repeatedly through fecaloral bird-to-bird transmission. We predicted that if WNV is found in the absence of mosquitoes, there would be evidence for regular bird-to-bird transmission through high rates of feather staining and prevalence of WNV in fecal specimens.

\section{Methods}

Study Site. We collected crow abundance data, crow carcasses, and fecal samples from a large overwintering crow roost, covering a $400 \mathrm{~m}^{2}$ area on the University of California, Davis campus $\left(38^{\circ} 53^{\prime} 90.60^{\prime \prime} \mathrm{N}\right.$, $121^{\circ} 75^{\prime} 72.94^{\prime \prime} \mathrm{W}$ ), Yolo County, CA, from January 2013 until August 2014. This time period encompassed two overwintering roost periods (January-March 2013 and October 2013-March 2014). The winter roosts were composed of both resident and migratory birds. We also collected feces from two additional winter roosts (within adjacent counties) in March 2014 (Yuba City, Sutter County, CA, $39^{\circ} 14^{\prime} 35.35^{\prime \prime} \mathrm{N},-121^{\circ}$ $63^{\prime} 29.06^{\prime \prime} \mathrm{W}$ and Sacramento, Sacramento County, CA, $\left.38^{\circ} 57^{\prime} 85.90^{\prime \prime} \mathrm{N},-121^{\circ} 48^{\prime} 67.71^{\prime \prime} \mathrm{W}\right)$. Local WNV prevalence in birds in the preceding summer season was high for both overwintering periods (593 and 301 WNV-infected dead birds were collected during summer in Sacramento, Yolo, and Sutter counties in 2012 and 2013, respectively http://diseasemaps.usgs. gov/wnv_ca_bird.html).

Crow Roost Counts and Seasonal Rate of Feather Staining. We quantified crows within the Davis roost site one to three times per week from 27 January 2013 through 15 April 2014. The majority (77\%) of these surveys were conducted by a single observer (MGH) with aid from three other observers. Surveys began $\sim 30$ min before sunrise, before crows began to leave the roost. During these surveys, we approximated the total number of crows roosting in each tree within the site and tallied our counts to estimate overall abundance. We quantified the percentage of birds with feces on their feathers from October 2013 through May 2014 at a staging area $200 \mathrm{~m}$ from the roost, where crows would flock on the ground to feed immediately after leaving the roost. Birds were observed using a spotting scope 10-30 min after sunrise, two to six times per month. The percentage of birds with visible fecal staining was recorded from a random subset within the flock (mean $\pm \mathrm{SE}=$ $42.3 \pm 2.8$; range: $17-100$ birds classified per observation period). Birds were classified as having fecal staining when white feces were conspicuous against black plumage.

Mosquito Abundance and WNV Testing. Mosquitoes were trapped in Davis between October 2013 and August 2014 to estimate seasonal mosquito activity near the Davis roost (hereafter "local mosquito activity"). We used three trapping methods: dry ice-baited traps (Newhouse et al. 1966), gravid traps (Cummings 1992), and aspiration collections from 
artificial shelters (Nasci 1981). Traps were set between 1200-1600 hours at four locations within the roost and at four comparison locations $250-800 \mathrm{~m}$ away from the roost (Fig. 1) and collected the following morning (30-60 min after sunrise). Comparison traps were used to account for diversion of host-seeking mosquitoes away from traps placed under avian roosts (Thiemann et al. 2011). Trap operation during afternoon in winter may detect females host-seeking before and during dusk. Mosquitoes were trapped once per week from October 2013 through early August 2014 except during periods of excessive rain or winds $(n=11$ of 41 weeks missed due to inclement weather) and were identified to species. In the present study, we captured low numbers of Culex pipiens L. and Culex tarsalis Coquillet. $C x$. pipiens populations in our study area are an admixture of $C x$. pipiens form pipiens, $C x$. pipiens form molestus Forskäl, and limited Culex quinquefasciatus (Kothera et al. 2013) that are morphologically indistinguishable and referred to here as $C x$. pipiens. Populations of $C x$. quinquefasciatus do not enter reproductive diapause (Nelms et al. 2013a,b). We included both species in our estimates of local mosquito activity, as either might contribute to local WNV transmission. Culex were pooled by species, week, and by nonroost or roost trapping site and stored at $-80^{\circ} \mathrm{C}$ prior to testing. Pools were tested for WNV RNA by qRT-PCR as described below.

We also summarized mosquito surveillance data from Davis, CA, provided by the Sacramento-Yolo Mosquito and Vector Control District integrated surveillance program (http://www.fightthebite.net/).
Mosquitoes were collected during spring and summer by either $\mathrm{CO}_{2}$ or gravid traps, which were run weekly from 2009-2014. Pools of up to 50 mosquitoes were tested for WNV by qRT-PCR and the infection rate per 1,000 females tested was calculated using a maximum likelihood estimate in Excel (Microsoft Corporation, Redmond, WA) using an add-in provided by the CDC (Biggerstaff 2003).

Fecal Collection. A total of 909 fecal samples were collected from the Davis overwintering roost: 495 fresh fecal samples were collected between 13 February-1 March 2013 and 414 samples were collected between October 2013 and March 2014. In March of 2014, we also collected 120 and 90 samples from large $(>4,000$ birds) roosts in Yuba City, CA, and Sacramento, CA, respectively. We also collected 263 samples from large ( $\geq 200$ birds) dawn and dusk staging groups, in which crows congregate before flying into the overnight roosts, in Davis during August and September of 2013, prior to the establishment of the winter roost. We considered fecal samples fresh if still moist at the time of collection; desiccated feces were disregarded. Sample collection was spread relatively evenly between August 2013 and March 2014 (60-175 samples collected each month; mode $=88$ per month). We used sterile cottontipped applicators to collect fresh feces under the roost trees within $\sim 1 \mathrm{~h}$ of sunrise. An effort was made to focus collection on feces that were actively observed striking the ground and those that appeared to be $<1 \mathrm{~h}$ old. Samples (containing all or a portion of the fecal matter deposited by a crow) were labeled individually and stored in 1-ml aliquots of viral transport media

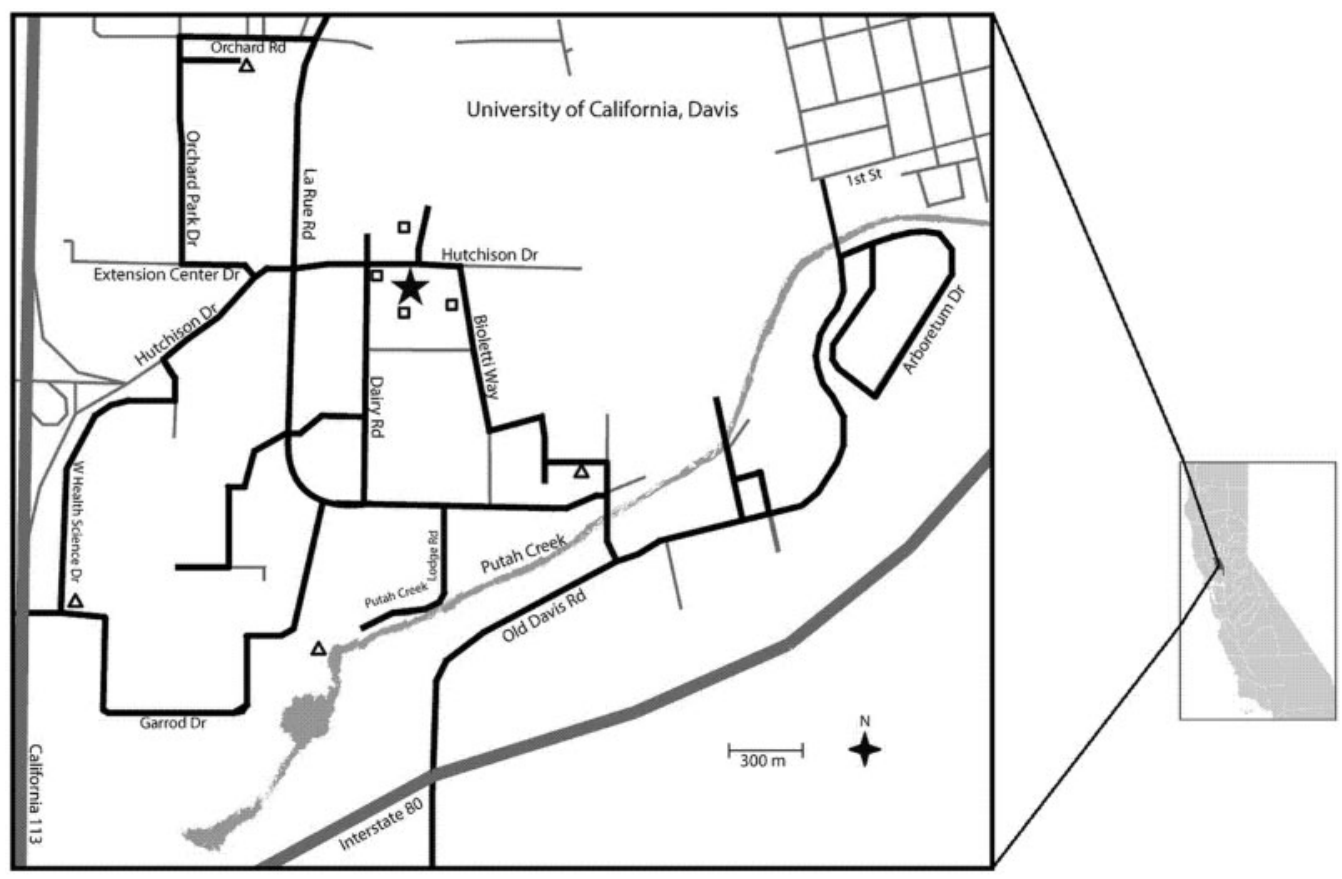

Fig. 1. A map of the focal study site at the University of California, Davis. The star indicates the location of the winter crow roost. Squares indicate roost mosquito trap locations, whereas triangles indicate nonroost trap locations. The carcass survey route is indicated by the bold lines. 
(VTM) from a stock solution of $500 \mathrm{ml}$ DMEM (Dulbecco's Modified Eagle's Medium), $10 \%$ heatinactivated fetal bovine serum (FBS), $0.05 \mathrm{mg} / \mathrm{ml}$ gentamicin sulfate, $500 \mathrm{U} / \mathrm{ml}$ penicillin, $0.5 \mathrm{mg} / \mathrm{ml}$ streptomycin, $2 \mu \mathrm{g} / \mathrm{ml}$ amphotericin B solution. Samples were stored at $-80^{\circ} \mathrm{C}$ prior to $\mathrm{WNV}$ testing.

Carcass Collection and Testing. We searched for crow carcasses along an established route encircling the Davis roost at least one to two times per week throughout the study (Fig. 1). Additionally, we collected local dead birds reported through a web-based carcass reporting system. Carcasses were stored at $-20^{\circ} \mathrm{C}$ until tested for WNV. A total of 62 carcasses were collected and tested during the study period. Eight carcasses were tested for WNV using oral swabs collected by the California Animal Health and Food Safety lab as part of the Dead Bird Program (http:// westnile.ca.gov/report_wnv.php). For the 54 remaining carcasses, both kidney samples (snips of kidney tissue of roughly equivalent size; estimated sizes of samples were no larger than $3 \mathrm{~mm}^{3}$ ) and cloacal swabs (cotton applicators were inserted into the cloaca and rotated 15 times) were tested for WNV RNA as indicated below. Samples were collected by two researchers from stored carcasses on 16-18 December 2013 and on 23 April 2014.

RT-PCR WNV Testing. RNA from mosquito, crow, and fecal samples was extracted using a MagMax Express Particle Processor and Viral Isolation kits following manufacture protocols (Life Technologies, Grand Island, NY). Extracted RNA was tested for WNV RNA by RT-PCR using a ViiA 7 Real-Time PCR system (Life Technologies) and SensiFAST One Step reagents (Bioline, Taunton, MA). Primers and probe that were specific for the envelope (Lanciotti et al. 2001) or NS1 (Shi et al. 2001) genes were used for screening and confirmation, respectively. Threshold cycle $\left(\mathrm{C}_{\mathrm{t}}\right)$ scores were recorded and analyzed (see below) for kidney sample and cloacal swab tests. $\mathrm{C}_{t}$ score is a relative measure of the concentration of target sequence in a qRT-PCR reaction; higher $C_{t}$ score correlates with a lower concentration of target in the qRT-PCR reaction (Life Technologies).

Statistical Analyses. All analyses were conducted using R (The R Core Team. 2013). The relationship between fecal staining and local crow abundance was examined using a generalized linear model (function glm in library MASS), with the proportion of stained birds as the response (weighted by the number of birds observed) and number of birds counted at the roost in the most recent count as the predictor (binomial distribution; $\beta \pm \mathrm{SE}$ given in logit form). We compared mean $\mathrm{CO}_{2}$ trap capture of $C x$. tarsalis versus $C x$. pipiens as well as combined Culex capture between roost and nonroost sites using Wilcoxon Signed Rank tests with a continuity correction (function wilcox.test). We also compared carcass kidney and cloacal swab $\mathrm{WNV} \mathrm{C}_{\mathrm{t}}$ scores using a paired $t$-test (function $t$ test). Percentages of WNV-positive carcasses before and during the winter roosting period were compared using a McNemar's test for marginal homogeneity with a continuity correction (function monemar.test). We also analyzed changes in kidney $\mathrm{C}_{\mathrm{t}}$ scores over time throughout the study period using a Linear Regression (function $\mathrm{lm}$ ). For our analyses, mosquito capture data and $\mathrm{C}_{\mathrm{t}}$ scores were log transformed to meet assumptions of equal variances and normality, respectively.

\section{Results}

Crow Roost Counts and Fecal Staining. Crow roost counts included two separate winter roosting periods (January-April 2013 and October-April 2013-2014) with a lull between 12 April 2013 and 23 October 2013, during which the communal roost dispersed (Fig. 2). The maximum roost sizes in the first and second overwintering roost periods were 10,190 and 7,075 crows, respectively. The percentage of birds in the roost with fecal staining ranged from 0\% (spring and fall, when crow counts at the roost were low) to $57.5 \%$ (mid-winter, when crow counts were at their peak). As expected, peak periods of fecal staining mirrored peaks of seasonal crow abundance: the percentage of stained birds increased with local crow abundance $[\beta$ estimate $(\%$ stained $/ 1,000$ birds present at the roost $\pm \mathrm{SE}=0.74 \pm 0.07, \quad z \quad(23)=11.12$, $P<0.0001]$.

Mosquito Abundance and WNV Testing. In total, we captured 720 mosquitoes (range of weekly captures: 0-120 mosquitoes), 482 of which were Culex (Culex tarsalis: 171 and Culex pipiens: 311). Capture varied with trap type, with the $\mathrm{CO}_{2}$ traps yielding the highest numbers of both Culex species (total $\mathrm{CO}_{2}$ trap yield: 333; Gravid trap yield: 142; resting trap yield: 7). For the following statistical analyses we compare yields from $\mathrm{CO}_{2}$ traps due to their consistency and reliability relative to the other two trap types throughout the study. Mean weekly capture did not significantly differ between the two Culex species (Wilcoxon signed rank test: $\mathrm{V}=85.5, P=0.3785)$. Culex species were captured infrequently during winter months, but numbers began to increase as temperatures increased in April (Fig. 2). During the winter roost period, mosquito capture within the roost did not significantly differ from capture at the non-roost sites (Wilcoxon signed rank test: $\mathrm{V}=10.5, P=0.605)$. All 37 pools that we collected (October 2013-August 2014) tested negative for WNV RNA.

Fecal Testing. Of the prewinter roost samples collected in August 2013, 2.3\% (2/88) tested positive for WNV (qRT-PCR $\mathrm{C}_{t}$ scores: 23.4 and 37.8); 0\% (0/132) of the samples collected in September tested positive. None of 1,119 winter (October-March) samples collected at roosts in 2013 and 2014 from Davis, Yuba City, and Sacramento tested positive for WNV RNA. The probability of this occurring given a baseline expectation of $2.3 \%$ (the prevalence of WNV positive feces in August 2013 when WNV activity begins to slow down) is $<0.0000001$ (Binomial Approximation via Poisson Distribution), suggesting that we would have detected WNV in our fecal samples, if it were occurring at a level of or above $2.3 \%$.

Crow Carcass Collection and Testing. We collected and tested a total of 62 carcasses throughout the 


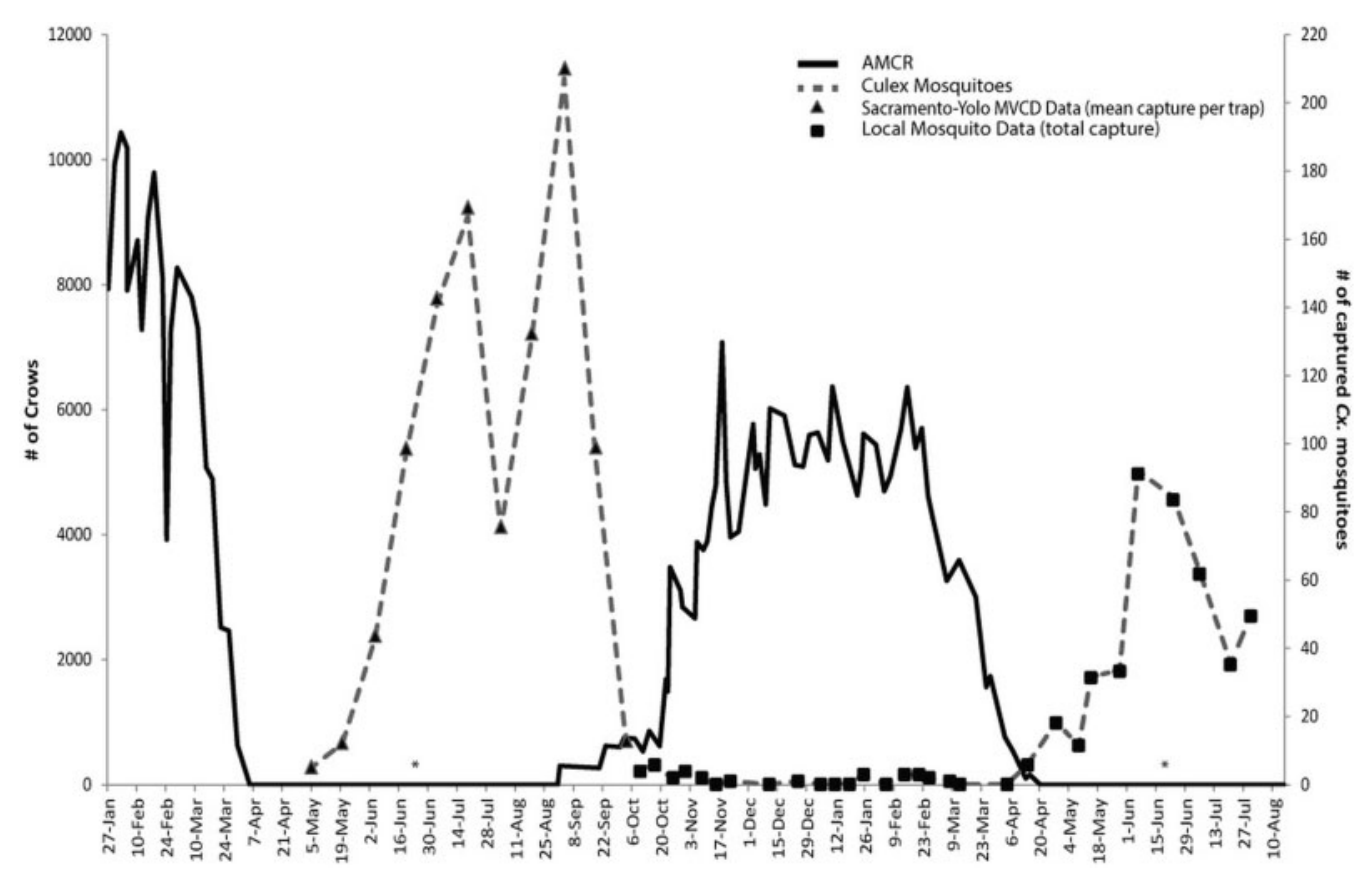

Fig. 2. Comparison of crow winter roost abundance and Culex mosquito capture from January 2013 to August 2014. The primary (left) y-axis depicts the number of crows counted within the winter roost across time beginning in January of 2013 and ending in April of 2014. The secondary (right) y-axis shows the number of captured Culex mosquitoes from May 2013-August 2014. Sacramento-Yolo Mosquito and Vector Control District mosquito data (mean dry ice trap capture) are indicated with triangles, whereas local mosquito data (overall capture numbers) are indicated with open squares. Peak crow numbers at the roost coincided with low Culex capture. * Due to lack of observed activity or fecal staining on substrate within the winter roost location during the summer, we set roost abundance to zero throughout this time. However, it is possible that some nonbreeding crows may have roosted within this site during the summer.

course of our study, $50 \%$ (31/62) of which were positive for WNV. Eighteen carcasses were collected prior to the winter roosting period [July-September, 13 (72\%) of which were WNV positive]. During the winter-roost period, $41 \%$ of carcasses tested were positive (18/44). Overall, WNV prevalence among carcasses during winter was significantly lower than preroost prevalence (McNemar's test for marginal homogeneity: $\chi^{2}=6.26$, $\mathrm{df}=1, P=0.012)$. Of the 44 carcasses collected during the winter roosting period (October-April), 32 (72.7\%) were collected under the roost and $12(37.5 \%)$ of these were positive for $\mathrm{WNV}$ (Fig. 3).

Of 54 carcasses collected and necropsied between 30 August 2013 and 23 March 2014, we were able to test both kidney and cloaca samples from 49 . We were only able to take one of the two samples from the five remaining carcasses due to state of decomposition at collection (in one of these birds maggots were tested in place of the kidney sample and this bird was removed from further analyses). Twenty-seven of $54(50 \%)$ carcasses tested positive for WNV RNA. Sixteen of 27 (59.2\%) positive carcasses had WNV RNA in both kidney and cloaca samples (for one of these birds maggots were tested in place of the kidney sample, this carcass was also removed from further analyses). The concentration of WNV RNA was significantly higher in the kidneys than in the cloaca: $\mathrm{C}_{\mathrm{t}}$ scores were significantly lower for kidney samples relative to cloaca samples (paired $t$-test: $t=-5.26, \mathrm{df}=14, P=0.00012$; Effect size: Cohen's $\mathrm{d}=0.82, r=0.38$ ). Additionally, kidney $\mathrm{C}_{\mathrm{t}}$ scores significantly increased as the winter roost period progressed (Fig. 4; Linear regression: $r^{2}=0.46$, $t=4.268, \quad \mathrm{df}=21 ; P=0.00034$ ), suggesting a lower amount of virus was present in positive carcasses during the winter roost period than in the summer. Seven carcasses tested positive in one sample type but not the other: five kidney samples tested positive while cloacal swabs were negative, and conversely two cloacal swabs tested positive but kidney samples were negative. These latter two birds had high $\mathrm{C}_{\mathrm{t}}$ scores (38.2 and 33.4) suggesting low viral loads.

\section{Discussion}

We documented WNV infection in crow carcasses throughout the year. Winter infections were unlikely to have arisen by recent bites from infected mosquitoes, because Culex mosquito activity was very low in winter and all mosquitoes collected during winter months tested negative for WNV. Similar mosquito results were reported recently for other sites within the Davis and Sacramento areas (Nelms et al. 2013b). In contrast, consistent opportunities existed for fecal-oral transfer at the overwintering roost. Of the carcasses for which 


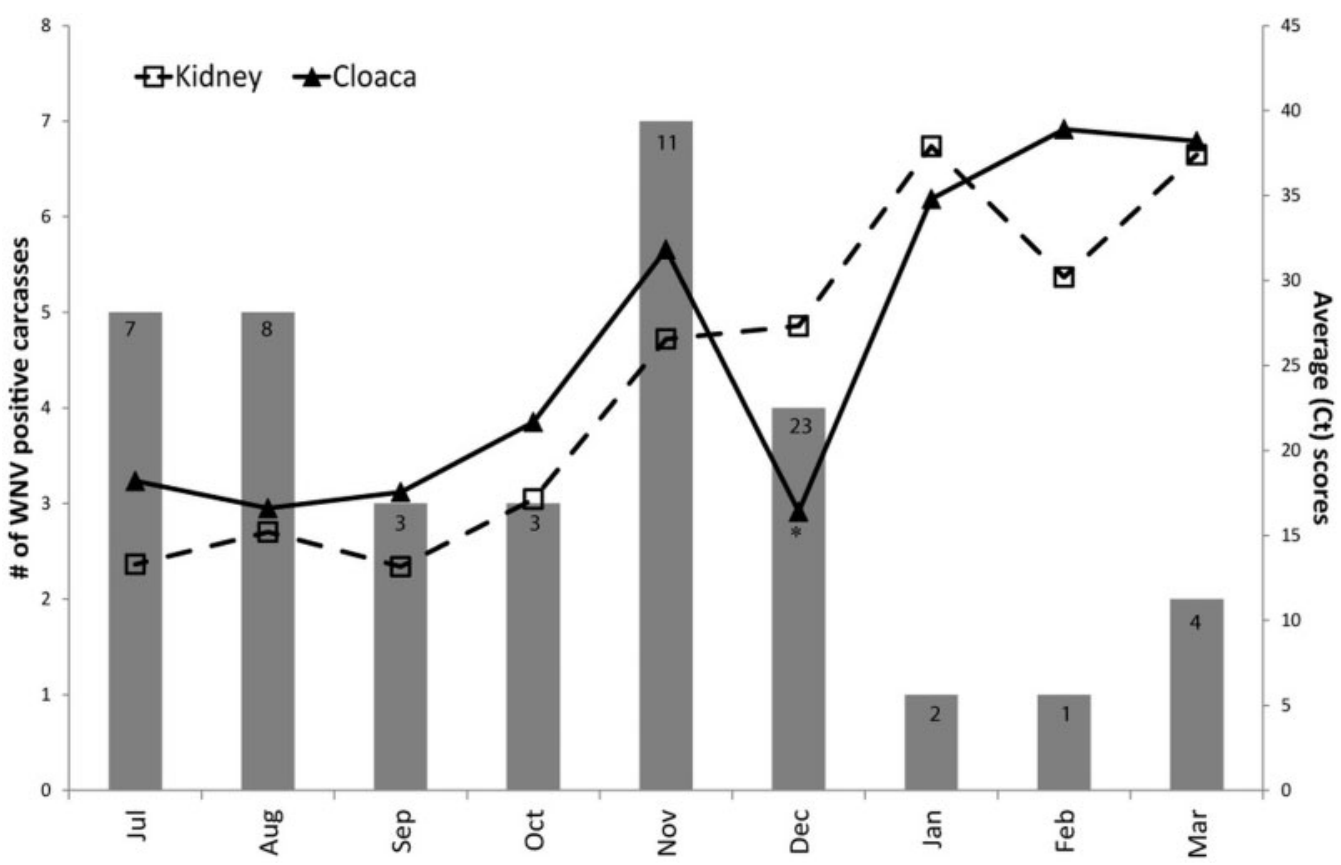

Fig. 3. Percentage of WNV-positive crow carcasses and average kidney and cloacal swab $\mathrm{C}_{\mathrm{t}}$ scores per month from July 2013 through March 2014. The primary (left) y-axis shows raw number of carcasses that tested positive for WNV each month. Numbers above each bar indicate the total number of carcasses collected that month. The secondary (right) y-axis indicates average $\mathrm{C}_{t}$ score. In July and August we found four WNV-positive carcasses for which we do not have Ct scores; these birds are included in the figure. The two WNV positive carcasses in March only tested positive in either the kidney or the cloacal swab, not both. * Only one of the four positive carcasses had a cloacal swab that tested positive for WNV RNA in December. This bird also had an uncharacteristically low kidney $\mathrm{C}_{t}$ relative to other winter carcasses. Therefore, reduction in cloacal swab $\mathrm{C}_{t}$ in December is the result of a single bird that most likely died of acute WNV infection, but this was a rare event in the winterroosting period.

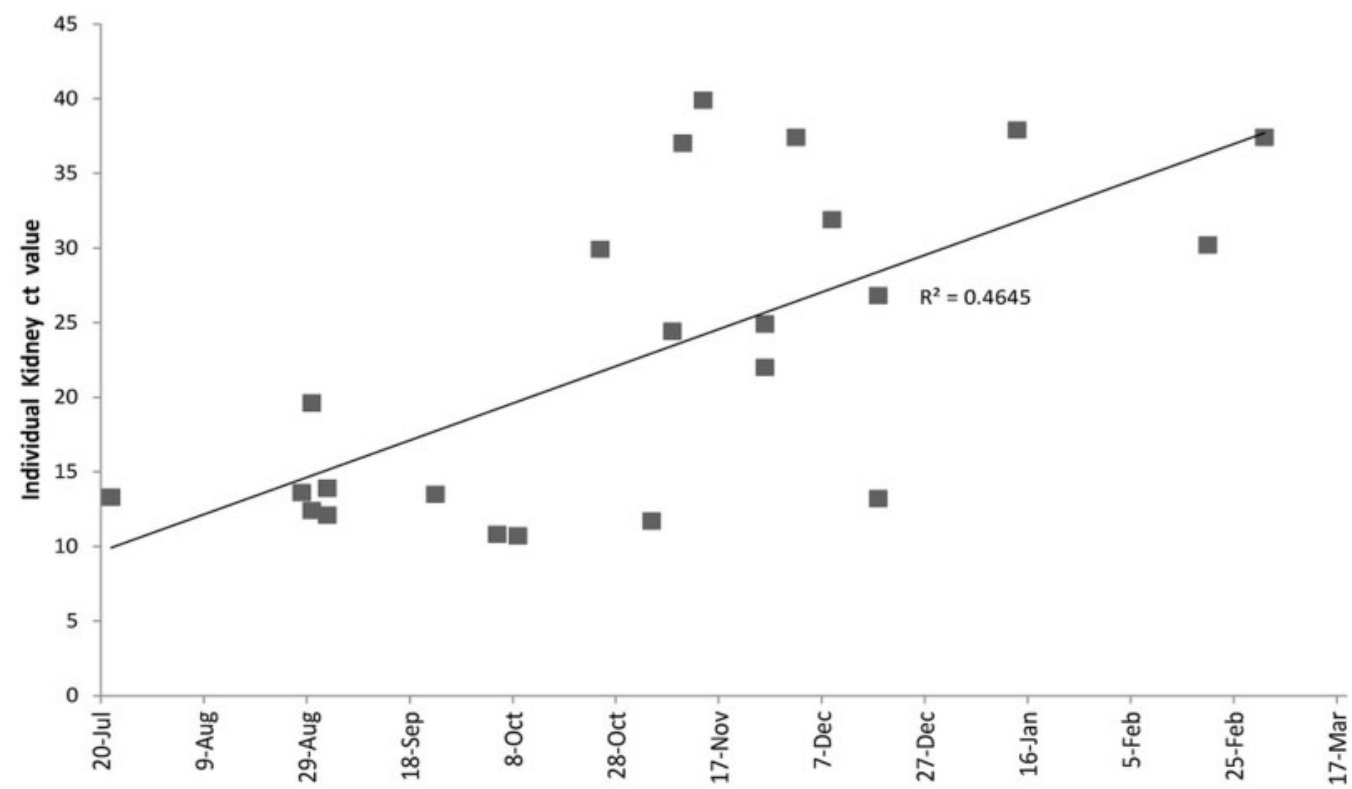

Fig. 4. Linear regression showing kidney $\mathrm{C}_{\mathrm{t}}$ scores of WNV-positive crow carcasses across time. 
both kidney samples and cloacal swabs were tested, most that tested positive for $\mathrm{WNV}$ had detectable viral RNA in both kidney and cloacal swabs. This suggests that WNV-infected crows were shedding virus in their feces, though perhaps at low concentrations (as Ct scores were significantly higher for cloacal swabs than in kidneys). Furthermore, peak periods of fecal staining and high midwinter crow numbers coincided, when $>50 \%$ of crows at the roost were stained with feces. Despite these clear opportunities for fecal-oral transmission, our study provided no evidence of WNV amplification overwinter and no direct evidence to suggest that fecal-oral transmission in overwintering crows was occurring frequently. Though there was active WNV transmission the preceding season, none of the $>1000$ feces collected from three roosts over two winters contained detectable WNV RNA.

It is possible that our sampling efforts were insufficient to detect low levels of bird-bird transmission that might have occurred through the winter. We did detect WNV among the 88 fecal samples taken under a staging group of crows in the late summer, when infected mosquitoes were active and the crow roost was relatively small ( $\sim 300$ birds). If we make the assumption that each sample was derived from a different bird, we sampled a maximum of $30 \%$ of the birds in the group, of which $2.3 \%$ were shedding WNV RNA at detectable levels. In contrast, we sampled 495 feces (all negative for $\mathrm{WNV}$ ) over a 1-mo period in late winter 2013 at the Davis roost when roost size was large ( 8000 birds; Fig. 2). Although (again assuming that each sample was derived from a different bird) only a maximum of $6 \%$ of birds in the roost were sampled, we still would have expected $\sim 10$ of these feces to test positive if the prevalence of WNV in the roost was maintained by horizontal transfer at the late-summer level (2.3\%). The expected number of positive samples would be even greater if $\mathrm{WNV}$ was amplified $\left(R_{o}>1\right)$ overwinter from bird-to-bird transmission. Likewise, we sampled 414 feces (all negative for WNV) over the winter of 2013-2014 at the Davis roost, when roost size was $\sim 5,500$ birds (a maximum of $7.5 \%$ of birds sampled; Fig. 2), of which we expected $\sim 9$ feces (or more, in the case of amplification) to test positive under the maintenance scenario. Indeed, the probability of finding no positives among all 1,119 winter samples across both years and all roost sites is $<0.0000001$ (given our expectation of a $2.3 \%$ prevalence). It is important to note that the prevalence of $2.3 \%$ may not be reflective of the actual rate of bird-to-bird transmission in late August and we cannot be certain whether this reflects prevalence that occurred during decline (basic rate of reproduction: $\left.R_{o}<1\right)$, maintenance $\left(R_{o}=1\right)$, or amplification $\left(\mathrm{R}_{\mathrm{o}}>1\right)$ of infection rates. Using this estimate, bird-to-bird transmission does not appear to amplify WNV above late-summer levels; however, we cannot rule out low levels of said transmission.

Another possible explanation for WNV infection observed among crows dying during winter is the persistence of WNV in birds surviving summer infection. In our study, kidney $\mathrm{C}_{\mathrm{t}}$ scores increased as the winter progressed (Fig. 4) and previous work has correlated elevated $\mathrm{C}_{\mathrm{t}}$ scores with $\mathrm{WNV}$ persistence rather than acute infection (Reisen et al. 2013). Persistent WNV infection has been documented in several other passerine species (Reisen et al. 2006a, Wheeler et al. 2012, Nemeth et al. 2009a,b), although not in crows (McLean et al. 2001, Komar et al. 2003, reviewed in Marra et al. 2004). Crows are highly susceptible to WNV, and most crows likely succumb to infection due to uncontrolled viral replication (Nemeth et al. 2011). Crows that died of WNV infection in the Davis population frequently had signs of coinfection (Wheeler et al. 2014), which may have led to even greater viral susceptibility. Still, there are several reports of antibody positive field-collected crows (Wilcox et al. 2007, Reed et al. 2009) and an unpublished study in 2010 in Orange County, CA, detected WNV antibodies in 5.6\% (6/108) of live captured crows (Morgan et al., unpublished data; R. Cummings, personal communication). Though this study has not been peer-reviewed and should therefore be taken with caution, these data suggest that in nature a low percentage of crows might survive infection.

Death of persistently infected birds (possibly due to coinfection or causes other than WNV), rather than those with newly acquired acute infection, may have been the primary source of WNV crow deaths that we observed in winter. Most carcasses that tested positive for WNV during the winter roost period had a kidney $\mathrm{C}_{\mathrm{t}}$ score over 20 (only three carcasses had kidney $\mathrm{C}_{\mathrm{t}}$ scores lower than 20 between November 2013 and March 2014). Additionally, the raw number of WNVpositive carcasses collected in the winter (18) was only marginally larger than the number collected between July and August of 2013 (13) despite the change in local crow population size. In the fall, as the winter roost is established, the Davis population of crows expands, most likely due to an influx of migrants (Marzluff et al. 2001). In conjunction, these two observations indicate a decrease in overall WNV infection rates during the winter. This follows expectations if mosquito vectors are an important source of infection for crows.

In temperate climates, winter temperatures are generally low, which, in conjunction with declining photoperiod, typically leads to Culex diapause or quiescence (Nelms et al. 2013b). We captured some Culex host-seeking during the winter, and therefore it is possible that mosquitoes may have contributed to WNV transmission to crows at the winter roost. In support, WNV was recovered from a single blood-fed Cx. tarsalis collected during January (Nelms et al. 2013b). Active mosquitoes should theoretically be able to find bloodmeals among the mass of crows that congregate at nocturnal winter roosts, and, if infected, mosquito-crow transmission could occur. However, it is improbable that crow-mosquito infection occurs. Large numbers of crows at nocturnal roosts (at maximum exceeding six thousand birds in the Davis roost) reduce the likelihood of contact between rare mosquito vectors and acutely infected crows. Moreover, low winter temperatures prevent or greatly delay virus replication thereby extending the extrinsic incubation period of the virus and effectively precluding transmission 
(Reisen et al. 2006c); in agreement, none of our pools collected in the winter tested positive for WNV RNA. However, none of our pools collected in the summer tested positive for WNV RNA. By comparison, the Sacramento-Yolo Mosquito and Vector Control District integrated surveillance program found mosquito pools positive for WNV RNA in the summers of 2013 (total of 13,990 individuals tested) and 2014 (total of 10,564 individuals tested). Peak percentages of WNV RNApositive pools occurred in July of both years with $15.6 \%(23 / 147)$ in 2013 and $23.3 \%$ (41/176) in 2014. It is therefore possible that we simply tested too few mosquitoes for us to detect WNV, even though it may have been present. Still, we think it unlikely that mosquitocrow transmission was occurring overwinter in our study site given low mosquito capture and relatively high $\mathrm{C}_{t}$ scores among WNV-positive crow carcasses.

Multiple studies have now documented the detection of WNV infected crows during winter (Tesh et al. 2004, Reisen et al. 2006a, Dawson et al. 2007, this study), but the mechanisms behind winter infection remain an enigma. We found no direct evidence to suggest that bird-to-bird transmission (via fecal-oral transmission) was an efficient or amplifying source of WNV infection in overwintering crow roosts sampled in California; none of the 1,119 feces that we collected in winter contained detectable viral RNA. Moreover, we felt that the likelihood of detecting virus in the feces of overwintering birds should have been relatively high in the years of our study because WNV activity (positive mosquitoes and crows) was consistent and high during the two preceding summer periods (http://westnile.ca.gov/; Fig. 3). Our findings do not, however, exclude the possibility that bird-to-bird transmission of WNV occurs occasionally at large nocturnal crow roosts, given the high frequency of fecal staining and the presence of virus in fecal samples collected in late summer. Indeed, one previous study in New York (Dawson et al. 2007) documented WNV RNA among 6.7\% of crow feces collected under a winter roost; however, a subset of these samples (10/55) were collected directly underneath carcasses of WNV-positive birds, which could have elevated their detection probability and the overall frequency of occurrence (at least one of three positive samples came from beneath carcasses). Interestingly, their results were similar to our $2.3 \%$ prevalence during late summer. In addition, winters in upstate New York were extremely cold, potentially preserving WNV RNA better than in our relatively warmer study area.

Though fecal-oral transmission among roosting birds may not be the driving mechanism of WNV maintenance overwinter, its presence among crows during this time suggests that winter roost sites are still potential points for vernal amplification of WNV once mosquito activity increases. Previous research suggests that mosquitoes do feed on crows during the spring and that dying crows lead to additional mosquito infection and later outbreaks (Nielsen and Reisen 2007a,b; Campbell et al. 2013). We suggest that future research examine the source of infection of winter cases of WNV in crows. Are these acute infections or the result of viral persistence? How often, if ever, do crows survive WNV infection? West Nile virus positive samples collected from wintering crows had significantly higher $\mathrm{C}_{t}$ scores indicating less target RNA was present in the sample. Are these high $\mathrm{C}_{t}$ scores evidence of persistent infection or can they be attributed to other unknown factors? Addressing these questions will provide more insight into the role that crows play in the overwintering of WNV and inform the response to winter detection of WNV in dead crows.

The role of crows in WNV amplification remains controversial, especially in light of infrequent reports of Culex bloodmeals positive for crows in the eastern United States where American Robins are a preferred host (Kilpatrick 2011). However, our research in California has clearly shown that during outbreaks the distribution of dead crows in time and space is strongly related to elevated mosquito infection rates and human cases (Kwan et al. 2010; Nielsen and Reisen 2007a,b; Reisen et al. 2006a), that infection in dead crows precedes seroprevalence rise in other passeriform species (Kwan et al. 2012), that elevated viremias undoubtedly increase the proportion of infected mosquitoes based on vector competence dose-response curves (Reisen et al. 2005), and that Culex feed frequently on crows during crow nesting and WNV vernal amplification resulting in elevated mosquito infection prevalence (Campbell et al. 2013). Collectively these data indicate an important role for crows in WNV amplification and potentially epidemic transmission when temperatures are permissive; however, the role of crows in WNV overwintering in California remains unresolved.

\section{Acknowledgments}

We would like to thank all of those who participated in our web-based carcass report system. Additionally we thank Ryane Logsdon, Conor Taff, Mojan Saberi, Young Suh, and Jacqueline Hurd for help with carcass collection, necropsy, and crow roost counts; Aaron Gabel, Kalene Morozumi, Mae Diapera, Johnny Saucedo, Kevin Krause, and Nora Noble-Christoff for help with setting and collecting mosquito traps; Robert Cummings for personal communications regarding unpublished crow WNV antibody data in Orange County, CA; and Ying Fang and Sandra Garcia, Center for Vectorborne Diseases, University of California Davis, for sample processing and testing. We also thank the California Animal Health and Food Safety (CAHFS) laboratory system at the University of California, Davis in association with the Center for Vectorborne Diseases (CVEC) for carcass testing as well as allowing us to use their facilities for necropsy. Additional surveillance data for Yolo and Sacramento counties was kindly provided by Dr. P. Macedo and staff of the Sacramento-Yolo Mosquito and Vector Control District. This work was supported by the Division of Agriculture and Natural Resources at the University of California at Davis and Research Grant AI55607 from the National Institute of Allergy and Infectious Diseases, NIH.

\section{References Cited}

Allan, B. F., R. B. Langerhans, W. A. Ryberg, W. J. Landesman, N. W. Griffin, R. S. Katz, B. J. Oberle, M. R. Schutzenhofer, K. N. Smyth, A. de St Mauric, et al. 2009. Ecological correlates of risk and incidence of West Nile virus in the United States. Oecologia 158: 699-708. 
Azad, H., and S. Thomas. 2004. West Nile encephalitis. Hosp. Physician 2004: 12-16.

Biggerstaff, B. J. 2003. Pooled infection rate. (www.cdc.gov/nci $\mathrm{dod} / \mathrm{dvbid} /$ westnile/software.htm)

Bowen, R. A., and N. M. Nemeth. 2007. Experimental infections with West Nile virus. Curr. Opin. Infect. Dis. 20: 293-297.

Campbell, G. L., A. A. Marfin, R. S. Lanciotti, and D. J. Gubler. 2002. West Nile virus. Lancet Infect. Dis. 2: 519-529.

Campbell, R., T. C. Thiemann, D. Lemenager, and W. K. Reisen. 2013. Host-selection patterns of Culex tarsalis (Diptera: Culicidae) determine the spatial heterogeneity of West Nile virus enzootic activity in northern California. J. Med. Entomol. 50: 1303-1309.

(CDC) Centers for Disease Control West Nile Virus Vertebrate Ecology [Internet]. 2009. Centers for disease control [cited 2013 April 21]. (http://www.cdc.gov/ncidod/dvbid/west nile/birdspecies.htm)

Cummings, R. 1992. Design and use of a modified Reiter gravid mosquito trap for mosquito-borne encephalitis surveillance in Los Angeles County, California. Proc. Mosq. Vector Control Assoc. Calif. 60: 170-176.

Dawson, J. R., W. B. Stone, G. D. Ebel, D. S. Young, D. S. Galinski, J. P. Pensabene, M. A. Franke, M. Eidson, and L. D. Kramer. 2007. Crow deaths caused by West Nile virus during winter. Emerg. Infect. Dis. 13: 1912-1914.

Dohm, D. J., M. L. O'Guinn, and M. J. Turell. 2002. Effect of environmental temperature on the ability of Culex pipiens (Diptera: Culicidae) to transmit West Nile virus. J. Med. Entomol. 39: 221-225.

Egizi, A. M., A. Farajollahi, and D. M. Fonsecca. 2014. Diverse host feeding on nesting birds may limit early-season West Nile virus amplification. Vector Borne Zoonotic Dis. 14: 447-453.

Eidson, M., N. Komar, F. Sorhage, R. Nelson, T. Talbot, F. Mostashari, and R. McLean. 2001. Crow deaths as a sentinel surveillance system for West Nile virus in the northeastern United States, 1999. Emerg. Infect. Dis. 7: 615-620.

Gorenzel, W. P., and T. P. Salmon. 1995. Characteristics of American crow urban roosts in California. J. Wildl. Manage. 59: 638.

Hamer, G. L., U. D. Kitron, T. L. Goldberg, J. D. Brawn, S. R. Loss, M. O. Ruiz, D. B. Hayes, and E. D. Walker. 2009. Host selection by Culex pipiens mosquitoes and West Nile virus amplification. Am. J. Trop. Med. Hyg. 80: 268-278.

Hartley, D. M., C. M. Barker, A. Le Menach, T. Niu, H. D. Gaff, W. K. Reisen. 2012. Effects of temperature on emergence and seasonality of West Nile virus in California. Am. J. Trop. Med. Hyg. 86: 884-894.

Ip, H. S., A. J. VanWettere, L. McFarlane, V. Shearn-Bochsler, S. L. Dickson, J. Baker, G. Hatch, K. Cavender, R. Long, and B. Bodenstein. 2014. West Nile virus transmission in winter: The 2013 great salt lake bald eagle and eared grebes mortality event. PLoS Curr. Outbreaks 1. doi: 10.1371/ currents.outbreaks.b0f031fc8db2a827d9da0f30f0766871.

Kilpatrick, A. M. 2011. Globalization, land use, and the invasion of West Nile virus. Science 334: 323-327.

Kipp, A. M., J. A. Lehman, R. A. Bowen, P. E. Fox, M. R. Stephens, K. Klenk, N. Komar, and M. L. Bunning. 2006. West Nile virus quantification in feces of experimentally infected American and fish crows. Am. J. Trop. Med. Hyg. 75: 688-690.

Komar, N. 2003. West Nile virus: Epidemiology and ecology in North America. Adv. Virus Res. 61: 185-234.

Komar, N., S. Langevin, S. Hinten, N. Nemeth, E. Edwards, D. Hettler, B. Davis, R. Bowen, and M. Bunning. 2003.
Experimental infection of North American birds with the New York 1999 strain of West Nile virus. Emerg. Infect. Dis. 9: 311-322.

Kothera, L., B. M. Nelms, W. K. Reisen, and H. M. Savage. 2013. Population genetic and admixture analyses of Culex pipiens complex (Diptera: Culicidae) populations in California, United States. Am. J. Trop. Med. Hyg. 89: 1154-1167.

Kwan, J. L., S. Kluh, M. B. Madon, and W. K. Reisen. 2010. West Nile virus emergence and persistence in Los Angeles, California, 2003-2008. Am J Trop Med Hyg 83: 400-412.

Kwan, J. L., S. Kluh, and W. K. Reisen. 2012. Antecedent avian immunity limits tangential transmission of West Nile virus to humans. PLoS One 7: e34127. doi: 10.1371/journal. pone.0034127.

Lanciotti, R. S., A. J. Kerst, R. S. Nasci, M. S. Godsey, C. J. Mitchell, H. M. Savage, N. Komar, N. A. Panella, B. C. Allen, K. E. Volpe, et al. 2000. Rapid detection of West Nile virus from human clinical specimens, field-collected mosquitoes, and avian samples by a TaqMan reverse transcriptase-PCR assay. J. Clin. Microbiol. 38: 4066-4071.

Lanciotti, R. S., and A. J. Kerst. 2001. Nucleic acid sequencebased amplification assays for rapid detection of West Nile and St. Louis encephalitis viruses. J. Clin. Microbiol. 39: 4506-4513.

Life Technologies. 2011. Real-time PCR: Understanding $\mathrm{C}_{\mathrm{t}}$. Applied Biosystems by Life Technologies, Carlsbad, CA. (http://www.lifetechnologies.com/us/en/home/life-science/pcr/ real-time-pcr/qpcr-education/pcr-understanding-ct-applica tion-note.html)

Lothrop, H. D., B. B. Lothrop, D. E. Gomsi, and W. K. Reisen. 2008. Intensive early season adulticide applications decrease arbovirus transmission throughout the Coachella Valley, Riverside County, California. Vector Borne Zoonotic Dis. 8: 475 .

Marra, P. P., S. Griffing, C. Caffrey, A. M. Kilpatrick, and R. McLean. 2004. West Nile virus and wildlife. BioScience 54: 393-402.

Marzluff, J. M., K. J. McGowan, R. Donnelly, and R. L. Knight. 2001. Causes and consequences of expanding American Crow populations, pp. 331-363. In J.M. Marzluff, R. Bowman, and R. Donelly (eds.), Avian ecology and conservation in an urbanizing world. Kluwer Academic Press, Norwell, MA.

McLean, R. G., S. R. Ubico, D. E. Docherty, W. R. Hansen, L. Sileo, and T. S. McNamara. 2001. West Nile virus transmission and ecology in birds. Ann. N. Y. Acad. Sci. 951: $54-57$.

Molaei, G., T. G. Andreadis, P. M. Armstrong, J. F. Anderson, and C. R. Vossbrinck. 2006. Host feeding patterns of Culex mosquitoes and West Nile virus transmission, northeastern United States. Emerg. Infect. Dis. 12: 468-474.

Nasci, R. S. 1981. A lightweight battery-powered aspirator for collecting resting mosquitoes in the field. Mosq. News. 41: 808-811.

Nelms, B. M., L. Kothera, T. Thiemann, P. A. Macedo, H. M. Savage, and W. K. Reisen. 2013a. Phenotypic variation among Culex pipiens complex (Diptera: Culicidae) populations from the Sacramento Valley, California: Horizontal and vertical transmission of West Nile virus, diapause potential, autogeny, and host selection. Am. J. Trop. Med. Hyg. 89: $1168-1178$.

Nelms, B. M., P. A. Macedo, L. Kothera, H. M. Savage, and W. K. Reisen. 2013b. Overwintering biology of Culex (Diptera: Culicidae) mosquitoes in the Sacramento Valley of California. J. Med. Entomol. 50: 773-790.

Nemeth, N., G. Young, C. Ndaluka, H. Bielefeldt-Ohmann, N. Komar, and R. Bowen. 2009a. Persistent West Nile virus infection in the house sparrow (Passer domesticus). Arch. Virol. 154: 783-789. 
Nemeth, N., P. T. Oesterle, and R. A. Bowen. $2009 \mathrm{~b}$. Humoral immunity to West Nile virus is long-lasting and protective in the house sparrow (Passer domesticus). Am. J. Trop. Med. Hyg. 80: 864-869.

Nemeth, N. M., B. V. Thomsen, T. R. Spraker, J. M. Benson, A. M. Bosco-Lauth, P. T. Oesterle, J. M. Bright, J. P. Muth, T. W. Campbell, T. L. Gidlewski, et al. 2011. Clinical and pathologic responses of American crows (Corvus brachyrhynchos) and fish crows (C ossifragus) to experimental West Nile virus infection. Vet. Pathol. 48: 1061-1074.

Newhouse, V., R. Chamberlain, J. Johnston, and W. Sudia. 1966. Use of dry ice to increase mosquito catches of the CDC miniature light trap. Mosq. News 26: 30-35.

Nielsen, C. F. and W. K. Reisen. 2007a. West Nile virusinfected dead corvids increase the risk of infection in Culex mosquitoes (Diptera: Culicidae) in domestic landscapes. J. Med. Entomol. 44:1067-1073.

Nielsen, C. F., and W. K. Reisen. 2007b. Dead birds increase the risk of West Nile Virus infection in Culex mosquitoes (Diptera: Culicidae) in Domestic Landscapes. J. Med. Entomol. 44: 1007-1013.

Petersen, L. R., P. J. Carson, B. J. Biggerstaff, B. Custer, S. M. Borchardt, and M. P. Busch. 2013. Estimated cumulative incidence of West Nile virus infection in US adults, 19992010. Epidemiol. Infect. 141:591-595.

Reed, L. M., M. A. Johansson, N. Panella, R. McLean, T. Creekmore, R. Puelle, and N. Komar. 2009. Declining mortality in American crows (Corvus brachyrhynchos) following natural West Nile virus infection. Avian Dis. 53: 458-461.

Reisen, W. K., Y. Fang, and V. M. Martinez. 2005. Avian host and mosquito (Diptera: Culicidae) vector competence determine the efficiency of West Nile and St. Louis Encephalitis virus transmission. J. Med. Entomol. 42: 367 $\neg 75$.

Reisen, W. K., C. M. Barker, R. Carney, H. D. Lothrop, S. S. Wheeler, J. L. Wilson, M. B. Madon, R. Takahashi, B. Carroll, S. Garcia, et al. 2006a. Role of corvids in epidemiology of West Nile virus in southern California. J. Med. Entomol. 43: 356-367.

Reisen, W. K., Y. Fang, and V. M. Martinez. 2006b. Effects of temperature on the transmission of West Nile virus by Culex tarsalis (Diptera: Culicidae). J. Med. Entomol. 43: 309-317.
Reisen, W. K., Y. Fang, H. D. Lothrop, V. M. Martinez, J. Wilson, P. O'Connor, R. Carney, B. Cahoon-Young, M. Shafii, and A. C. Brault. 2006c. Overwintering of West Nile virus in southern California. J. Med. Entomol. 43: 344-355.

Reisen, W. K., K. Padgett, Y. Fang, L. Woods, L. Foss, J. Anderson, and V. Kramer. 2013. Chronic infections of West Nile virus detected in California dead birds. Vector Borne Zoonotic 13: 401-405.

Shi, P. Y., E. B. Kauffman, P. Ren, A. Felton, J. H. Tai, A. P. DuPuis, S. A. Jones, K. A. Ngo, D. C. Nicholas, J. Maffei, et al. 2001. High-throughput detection of West Nile virus RNA. J. Clin. Microbiol. 39: 1264-1271.

Tesh, R. B., R. Parsons, M. Siirin, Y. Randle, C. Sargent, H. Guzman, T. Wuithiranyagool, S. Higgs, D. L. Vanlandingham, A. A. Bala, et al. 2004. Year-round West Nile virus activity, Gulf Coast region, Texas and Louisiana. Emerg. Infect. Dis. 10: 1649-1652

Thiemann, T., B. Nelms, and W. K. Reisen. 2011. Bloodmeal host congregation and landscape structure impact the estimation of female mosquito (Diptera: Culicidae) abundance using dry ice-baited traps. J. Med. Entomol. 48: 513-517.

The R Core Team. 2013. R: A language and environment for statistical computing. Version 3.0.1 (2013-05-16). R foundation for Statistical Computing. (http://web.mit.edu/r_v3.0.1/ fullrefman.pdf)

Wheeler, S. S., M. P. Vineyard, C. M. Barker, and W. K. Reisen. 2012. Importance of recrudescent avian infection in West Nile virus overwintering: Incomplete antibody neutralization of virus allows infrequent vector infection. J. Med. Entomol. 4: 895-902.

Wheeler, S.S., L. Woods, W.M. Boyce, C.D. Eckstrand, S. Langevin, B. Reisen, and A.K. Townsend. 2014. West Nile virus and non-West Nile virus mortality and coinfection of American crows (Corvus brachyrhynchos) in California. Avian Dis. 58: 255-261.

Wilcox, B. R., M. J. Yabsley, A. E. Ellis, D. E. Stallknecht, and S.E.J. Gibbs. 2007. West Nile virus antibody prevalence in American crows (Corvus brachyrhynchos) and fish crows (Corvus ossifragus) in Georgia, USA. Avian Dis. 51: $125-128$

Received 22 September 2014; accepted 11 March 2015. 